\title{
Review of Technology Adoption Models and Theories to Measure Readiness and Acceptable Use of Technology in a Business Organization
}

\author{
Thando Dube, Rene Van Eck, Tranos Zuva \\ Department of ICT, Vaal University of Technology \\ Vanderbijlpark, South Africa \\ thando.dube@ekurhuleni.gov.za, rene@vut.ac.za,tranosz@vut.ac.za
}

\begin{abstract}
It has been evident that innovative technologies have evolved in the past few decades, notably, in the computing discipline. As a result, technology adoption models and theories are deemed vital to business organizations to assess if end users are ready and accept new technologies. Therefore, requirements to review prevailing technology adoption models and theories which seek to assist business organizations to assess the readiness and acceptance of these new technologies, otherwise, such initiatives become obsolete and do not support core business processes, as it was originally intended. This paper reviews three technology adoption models relevant to information systems and information technology studies on the latest technologies such as ERP, cloud computing, and other systems implemented in business organizations. The study could assist to analyse the acceptance and utilization of new technologies. It can also be used to improve such models and theories in the adoption of new technologies.
\end{abstract}

Keywords: Technology adoption models, technology acceptance theories, technology acceptance model (TAM), technologyorganization-environment (TOE), unified theory of acceptance and use of technology (UTAUT)

\section{Introduction}

In the past few years, the computing discipline has massively progress particularly in the information systems (IS) and information technology (IT) areas, completely altered our backgrounds and the manner in which people generally cooperate with each other and the manner in which an organization conduct business, mostly, in a noble way (LeRouge \& Webb, 2004). Newly adopted technologies are extensively implemented, installed, and used by numerous organizations who pursue to improve an organization's business processes, information, and data between departments within an organization, also by assisting an organization to outperform its competitors (Kr \& Prakash, 2011). Even though the adoption of new technology creates opportunities in business, by making possible what was not possible before, it could, however, generate problems by disturbing the routines and processes, of the way employees of an organization, such as system users, are used to conduct their tasks in a particular way. Adopted technology is unpredictable and it could have a negative impact on an organization in a way that newly implemented systems might end up not being used (Sternad \& Bobek, 2013). Users get comfortable in using their old systems and they might hesitate to use the newly adopted system due to the fear of making mistakes (Kankanhalli, 2016). Not all users react the same way, some users are reasonably innovative, tactical, and are ready to consider the benefits presented to them, but others are content to carry on doing things in the same way in which they always have and they do not see a need to adopt new technology (Soh et al., 2000). Technology adoption has been studied widely in the area of information systems (IS). The aim of many studies on technology adoption has been at identifying, predicting, and describing variables that affect adoption behavior both in individuals and in organizations to embrace and implement technological innovations. As a result, frameworks and conceptual models were developed which assist in understanding the association of the acceptance behavior variables. This paper, therefore, seeks to review these studies, examine the effect of the TOE, TAM, and UTAUT to clarify the adoption of technology and their narrow descriptive influence. This study, therefore, identifies the variables enlightening the recent technologies adoption such as enterprise resource plan (ERP), radio-frequency identification (RFID), electronic data interchange (EDI), knowledge management (KM) and review the challenges, issues of the models, the capacity to gain an accurate and deep understanding of models used to measure the acceptance of the adopted technology (Gangwar et al., 2014). In this paper, we have 
Journal of Information Technology and Digital World (2020)

Vol.02/ No. 04

Pages: 207-212

https://www.irojournals.com/itdw/

DOI: https://doi.org/10.36548/jitdw.2020.4.003

considered the organization-based findings founded on UTAUT, TAM, and TOE. Hence this paper is based on an overview of the three prevailing technology adoption models and theories: TAM, TOE, and UTAUT.

\section{Methodology}

This paper comprehensively reviews and explores three technology adoption models and theories relevant to IS and IT studies published between 2003 and 2018. It focuses on the latest information technologies (IT's) such as e-commerce, enterprise resource, ERP systems, biometric systems, cloud computing, IoT, and KM systems deployed in business organizations, to assist the researcher to better explain such models, to categorically select an ideal model for this study to assess a new technology prior deployment to lessen IT project failures and ITrelated wasteful expenditure. To ensure that this paper does not miss out on vital studies, researchers further search available sources using search criteria comprising of the full names of the three models and its abbreviations: "technology acceptance model", "technology-organization-environment" and "unified theory of acceptance and use of technology" and other variants such as "technology adoption, individual acceptance and use of IT, ease of use of IT". This paper only focuses on IS and IT technologies adoption models and theories papers with an emphasis on technology adoption in both IS and IT fields.

\section{Background}

According to Khasawneh (2008) technology adoption is defined as the first use or acceptance of new technology or new system. Technology adoption is clarified by numerous theories and models such as the technology acceptance model (TAM), innovation diffusion theory (IDT), the theory of reasoned action (TRA), Theory of Planned Behaviour (TPB), technology-organization-environment (TOE); and unified theory of acceptance and use of technology (UTAUT).

Zhenhua et al (2008) have categorized adoption into three echelons: organizations, groups, and individuals. TAM, UTAUT, and TOE are extensively used in reviewing the adoption of technology by the side of the organizational level. However many studies have found TAM as an effective, vigorous, and extremely leading model in predicting the adoption of technology by the side of the organizational level (King \& He, 2006). Many reviews of TAM studies conceded that TAM and its modified versions expanded substantial theoretical and practical provision, hence they are the most extensively used by IS researchers as opposed to alternative models (AmoakoGyampah \& Salam, 2004; Legris et al., 2003). TAM has numerous advantages such as it is frank and intended to deliver a suitable clarification and a prediction of various users' acceptance of IT in organizational contexts, it has been studied well and it is a leading model for inspecting technology adoption (Carr et al., 2010). Studies have argued that UTAUT was designed for foreseeing the adoption of technology at the individual level, however, there are some few studies at the organizational level (Oliveira et al., 2011; Williams et al., 2009; Zhenhua et al., 2008). Hence, the TOE framework was developed as a prevalent theoretical view of technology adoption in IT, numerous authors have verified its variables for the acceptance of numerous technologies (Thiesse et al., 2011; Wang \& Chen, 2006). Oliveira et al (2011) state that, IDT theories are similar to the organizational context and expertise of the TOE framework, though TOE is more significant than IDT as per the analysis of (Zhu et al., 2003). This paper will review UTAUT, TAM, and TOE.

\section{Technology acceptance model (TAM)}

TAM is the technology adoption model that has been extensively used and studied for predicting the adoption and use of the adopted technology in an organization. Many studies on adopting new technologies have engaged TAM and they all prove that TAM is an extensively appropriate model that describes the reasonable extent of the adjustment in the adoption of technology and use (Au \& Zafar, 2008; L. Da Chen \& Tan, 2004).

TAM speculates that technology adoption is determined by perceived usefulness and perceived ease of use. Perceived usefulness is defined as "the degree to which an employee of an organization believes that using a particular system would enhance his job performance", and perceived ease of use is defined as "the degree to which an employee of an organization believes that using a particular system would be free of effort" (Au \& Zafar, 2008). In TAM, an employee's perception of the usefulness and ease of use of a new technology defines an employee's attitude towards using the new technology, which in turn defines whether an employee has an intention to use the newly adopted technology and continue using it (Schillewaert et al., 2005). TAM is based on the theories of reasoned action and planned behavior, which differentiates between principles, attitudes, beliefs, and intentions (Au \& Zafar, 2008). In addition to the effect of perceived ease of use on attitude toward using, TAM also speculates that perceived ease of use influences perceived usefulness. The simpler to use the newly adopted system is perceived as more useful. 
Journal of Information Technology and Digital World (2020)

Vol.02/ No. 04

Pages: 207-212

https://www.irojournals.com/itdw/

DOI: https://doi.org/10.36548/jitdw.2020.4.003

TAM was initially created to predict users' acceptance of the new technology, TAM is anticipated to clarify and predict the behavior of the employee in the future, as well as its importance in post-adoption surveys, has been endorsed (Hong et al., 2006). It can therefore be inferred that the TAM model has clear insinuations from both hypothetical and practical perceptions on technology adoption.

\section{Limitations and challenges of TAM}

TAM has been found with some challenges. Contradictory findings have been produced by studies on TAM and have caused misunderstanding on curbing and peripheral variables (L. Da Chen \& Tan, 2004). TAM calculates the perceived adoption of upcoming behavior, not actual behavior ( $\mathrm{Wu}, 2011)$. TAM has a limited probability for description and prediction, and deficiency for concrete value (Garača, 2011). Therefore, there is a point for examining the scope of some variables, like the role of a company's degree for technology readiness, security, and assessing the outcomes of the use of technology (Autry et al., 2010; Wu, 2011). Subsequently, most of the technology adoption studies utilized the TAM model. Williams et al. (2009) emphasized that empirical studies based on TAM do not produce absolute steady or strong results; therefore, important elements need to be recognized and included in the models. This illustrates the need to incorporate the TAM model with other theories and their adoption models.

\section{Technology-organization-environment (TOE) framework}

TOE framework was developed by Tornatzky (1990) to study the technology adoption of numerous IS and IT services and products at the organizational level. It has risen as an extensive theoretical viewpoint on IT adoption (Zhu et al., 2004). The addition of organizational, technological, and environmental variables had made TOE beneficial over other models used in the study of the adoption of technology, the use of technology, and worth creation from innovation in technology (Hossain \& Quaddus, 2011; Zhu, K. and Kraemer, 2005). Moreover, it is free from restrictions on business and organization's size (J. Chen et al., 2010). Hence, it offers a complete image of the user's adoption of technology, its execution, the expected obstacles, its effect on value chain operations, the dissemination amongst companies after adoption, factors impacting business innovation adoption choices, and to grow better organizational capabilities utilizing the technology (Salwani et al., 2009; Zhu et al., 2004).

According to Tornatzky (1990), There are around three types of contexts that can have an effect on technology acceptance, creativity, and implementation. These three TOE framework contexts are explained as follows:

(i) The technological context includes the variables that affect a person, an organization, and the adoption of innovations by a business (Claycomb et al., 2005). It comprises some innovation characteristics from IDT, that impact the possibility of adoption (Dedrick \& West, 2003). Apart from innovation qualities, investigators have incorporated a few different variables also. The studies establish that system integration, complication, perceived intended benefits, perceived unintended benefits, and standardization are important variables while observation is found irrelevant (Hossain \& Quaddus, 2011; Musawa \& Wahab, 2012).

(ii) Organizational context. Specifically refers to concise measures relating to organizations, for example, size, scope, and executives principles (Salwani et al., 2009). Adoption inclination is affected by formal and casual intrahierarchical systems for correspondence and control; alongside assets and creativity of the company (Dedrick \& West, 2003). The huge variables in business scenery incorporate money related assets, top administration support, company's structure, business's slack, development limit, information ability, operational ability, vital utilization of innovation, trust, mechanical assets, support for advancement, nature of human capital, hierarchical information collection, aptitude and framework and authoritative preparation while budgetary limit and innovation fitness are recognized as inconsequential (Hossain \& Quaddus, 2011; Musawa \& Wahab, 2012). Firm size was recognized as critical in RFID, web-based business, and ERP selection while unimportant in EDI appropriation (Hossain \& Quaddus, 2011). The explanation clarified by the creators is, associations of all sizes have understood the key significance of innovation for the achievement of their organizations, in this way are eager to contribute vigorously to advancements to improve their upper hands. Also, the job of top administration responsibility fluctuates from setting to setting (Huang et al., 2008). Some organizational factors are also studied in context on EDI by (Huang et al., 2008) who distinguished possible intensity of the accomplice, trust in the accomplice, and relationship duty with an accomplice as critical factors while the practiced intensity of the accomplice and reliance on the accomplice as irrelevant factors. Along these lines, it presents a comprehensive image of factors having sway on ongoing advancements.

(iii) Environmental context. It emphasizes on areas in which a company leads its business tasks, with the need given to outside elements affecting the business, for example, government motivating incentive and guidelines (Salwani et al., 2009). It incorporates factors identified with industry qualities, for example, competition, relations with purchasers and providers, just as the phases of the business life cycle (LeRouge \& Webb, 2004). Huge factors 
Journal of Information Technology and Digital World (2020)

Vol.02/ No. 04

Pages: 207-212

https://www.irojournals.com/itdw/

DOI: https://doi.org/10.36548/jitdw.2020.4.003

in natural setting incorporate client command, serious weight, outer weight, interior weight, exchanging accomplice pressure, seller support, business reliance, ecological vulnerability, data force, and system power while government guideline isn't distinguished as a noteworthy variable (Hossain \& Quaddus, 2011; Musawa \& Wahab, 2012). In this way, it presents a comprehensive image of factors having an influence on recent technologies.

\section{Limitations and challenges of TOE framework}

Studies based on TOE framework have numerous restrictions. As indicated by Dedrick \& West (2003), TOE framework is only a scientific classification for classifying variables and it doesn't represent the integrated theoretical framework or well-established theory, therefore, there is a need for a strong framework to examine technology adoption in organizations. Low et al (2011) moreover presented that TOE framework does not have main constructs in a model and variables in one and all context. The TOE framework is insufficient in its descriptive capacity of the adoption of technology, while it can be realized in the circumstance of EDI adoption where nearly half of the levels of EDI acceptance fluctuation stay mysterious (Musawa \& Wahab, 2012). Similarly, Wang et al. (2008) claimed that the TOE framework partakes uncertain key concepts, as well as TOE framework variables that fluctuate in context. Therefore, certain variables, such as sociological variables, psychological variables, technical readiness should be integrated to advance the TOE framework, factors notable to the nation setting, for example, government strategy/guideline, innovation framework and culture (Hossain \& Quaddus, 2011; Zhu et al., 2004).

\section{Unified theory of acceptance and use of technology (UTAUT)}

The unified theory of acceptance and use of technology (UTAUT) model was derived more than a decade ago, it is extensively used in the IS field, other fields and there are numerous citations about the original paper which introduced UTAUT and theory shreds of evidence that this model is extensively used in many fields (Venkatesh, 2016). Dwivedi et al (2011) stated that UTAUT enables the analysis to evaluate the user's intent to use an IS and behavior resulting from using an IS or technology. UTAUT refine the key factors and contingencies especially those which relate to the expected behavior intent to use of technology and technology use mainly to organizational contexts (Venkatesh, 2016).

Venkatesh (2016) contends that individual acceptance and use of IT is one of the most mature, robust, and reputable research in the IS field. According to Venkatesh (2016), UTAUT categorizes four vital factors and these factors are: quality expectations, effort expectations, social impact, and conditions facilitating, and four moderators are: age, gender, experience, and voluntarism, all of these factors and moderators contribute to considering behavioral involvement in the use of technology and actual use of technology mostly within an organization's contexts. Oshlyansky et al (2007) argue that UTAUT is a robust model and it can withstand translation; it can also be used cross-culturally regardless of its origin country and its language. UTAUT combines different IT acceptance models and theories, this extensive exercise was successfully completed in 2003 and they integrated the features of eight known models: (i) Theory of Reasoned Action, (ii) TAM, (ii) Motivational Model, (iv) TPB, (v) Combined TAM-TPB, (vi) Model of PC Utilization, (vii) Innovation Diffusion Theory, and (viii) Social Cognitive Theory (Anderson \& Schwager, 2003).

\section{Limitations and challenges of UTAUT}

Oshlyansky et al (2007) argue that a valid measure of scale to perceive and predict user acceptance of computers and new technologies is not adequate, therefore, there is a requirement to develop and validate a new scale of measure. Dwivedi et al (2011) UTAUT has been most cited by many studies, however, a systematic analysis depicts that a small number of these articles actually use this model. Most of the subjective available measures of scale which are currently in use are unvalidated and their relationship to technology or system usage is always unknown (Oshlyansky et al., 2007).

\section{Conclusion}

The above discussion of technology adoption models and theories based on the literature review comprehend diverse opinions and clarifications. The review shares the difference of technology adoption models and theories with different theoretical insights, limitations, and variables

This paper clarifies that integrating models, with the aim of developing another model, has appeared like a novel tendency in IS associated studies and has been verified to be valuable while taking into consideration the restrictions of several technology adoption models and theories (Hongjun and $\mathrm{Xu}, 2010$ ). The review moreover concludes that the concept of an integrated model is endorsed by existing frameworks and hypotheses of

Information Technology $\&$ 
Vol.02/ No. 04

Pages: 207-212

https://www.irojournals.com/itdw/

DOI: https://doi.org/10.36548/jitdw.2020.4.003

innovation, which are slight significant in clarifying technological acceptance for the new technologies such as ecommerce, enterprise resource, ERP systems, biometric systems, cloud computing, IoT, and KM systems at a business organizational level and hence there is a requirement for new emerging models and theories to analyze the acceptance and utilization of IT systems and technologies.

\section{References}

[1] Amoako-Gyampah, K., \& Salam, A. F. (2004). An extension of the technology acceptance model in an ERP implementation environment. Information and Management. https://doi.org/10.1016/j.im.2003.08.010

[2] Anderson, J. E., \& Schwager, P. H. (2003). Sme a Doption O F W Ireless Lan T Echnology : a Pplying T He Utaut M Odel. Information Systems, 39-43.

[3] Au, Y. a, \& Zafar, H. (2008). A Multi-Country Assessment of Mobile Payment Adoption. In Working Paper SERIES. https://doi.org/10.1111/1467-8616.00112

[4] Autry, C. W., Grawe, S. J., Daugherty, P. J., \& Richey, R. G. (2010). The effects of technological turbulence and breadth on supply chain technology acceptance and adoption. Journal of Operations Management. https://doi.org/10.1016/j.jom.2010.03.001

[5] Carr, A. S., Zhang, M., Klopping, I., \& Min, H. (2010). RFID Technology: Implications for Healthcare Organizations. American Journal of Business. https://doi.org/10.1108/19355181201000008

[6] Chen, L. Da, \& Tan, J. (2004). Technology adaptation in E-commerce: Key determinants of virtual stores acceptance. European Management Journal. https://doi.org/10.1016/j.emj.2003.11.014

[7] Chen, J., Phan, T. G., \& Reutens, D. C. (2010). Ridge penalized logistical and ordinal partial least squares regression for predicting stroke deficit from infarct topography. Journal of Biomedical Science and Engineering, 03(06), 568-575. https://doi.org/10.4236/jbise.2010.36079

[8] Claycomb, C., Iyer, K., \& Germain, R. (2005). Predicting the level of B2B e-commerce in industrial organizations. Industrial Marketing Management. https://doi.org/10.1016/j.indmarman.2004.01.009

[9] Dedrick, J., \& West, J. (2003). Why firms adopt open source platforms: a grounded theory of innovation and standards adoption. MISQ Special Issue Workshop: Standard Making: A Critical Research Frontier for Information Systems.

[10] Dwivedi, Y. K., Rana, N. P., Chen, H., \& Williams, M. D. (2011). A meta-analysis of the unified theory of acceptance and use of technology (UTAUT). IFIP Advances in Information and Communication Technology, 366, 155-170. https://doi.org/10.1007/978-3-642-24148-2_10

[11] Gangwar, H., Date, H., \& Raoot, A. D. (2014). Review on IT adoption: Insights from recent technologies. Journal of Enterprise Information Management, 27(4), 488-502. https://doi.org/10.1108/JEIM-08-20120047

[12] Garača, Ž. (2011). Factors related to the intended use of ERP systems. Management.

[13] Hong, S. J., Thong, J. Y. L., \& Tam, K. Y. (2006). Understanding continued information technology usage behavior: A comparison of three models in the context of mobile internet. Decision Support Systems. https://doi.org/10.1016/j.dss.2006.03.009

[14] Hossain, M. A., \& Quaddus, M. (2011). The adoption and continued usage intention of RFID: An integrated framework. Information Technology and People. https://doi.org/10.1108/09593841111158365

[15] Huang, Z., Janz, B. D., \& Frolick, M. N. (2008). A comprehensive examination of Internet-EDI adoption. Information Systems Management. https://doi.org/10.1080/10580530802151228

[16] Kankanhalli, K. \&. (2016). INVESTIGATING USER RESISTANCE TO INFORMATION SYSTEMS IMPLEMENTATION: A STATUS QUO BIAS PERSPECTIVE. Global Business Review, 17(4), 821833. https://doi.org/10.1177/0972150916645680

[17] Khasawneh, A. M. (2008). Concepts and measurements of innovativeness: the case of information and communication technologies. International Journal of Arab Culture, Management and Sustainable Development. https://doi.org/10.1504/ijacmsd.2008.020487

[18] King, W. R., \& He, J. (2006). A meta-analysis of the technology acceptance model. Information and Management. https://doi.org/10.1016/j.im.2006.05.003

[19] Kr, A., \& Prakash, O. (2011). A STUDY OF ISSUES AFFECTING ERP IMPLEMENTATION IN SMEs.

[20] Legris, P., Ingham, J., \& Collerette, P. (2003). Why do people use information technology? A critical review of the technology acceptance model. Information and Management. https://doi.org/10.1016/S03787206(01)00143-4

[21] LeRouge, C., \& Webb, H. (2004). Appropriating enterprise resource planning systems in colleges of business: extending adaptive structuration theory for testability. Journal of Information Systems Education.

[22] Low, C., Chen, Y., \& Wu, M. (2011). Understanding the determinants of cloud computing adoption. 
Vol.02/ No. 04

Pages: 207-212

https://www.irojournals.com/itdw/

DOI: https://doi.org/10.36548/jitdw.2020.4.003

Industrial Management and Data Systems. https://doi.org/10.1108/02635571111161262

[23] Musawa, M. S., \& Wahab, E. (2012). The adoption of electronic data interchange (EDI) technology by Nigerian SMEs: A conceptual framework. Journal of Business Management and Economics.

[24] Oliveira, T., Martins, M. F., \& Lisboa, U. N. De. (2011). Literature Review of Information Technology Adoption Models at Firm Level. Review of Economics Studies.

[25] Oshlyansky, L., Cairns, P., \& Thimbleby, H. (2007). Validating the Unified Theory of Acceptance and Use of Technology (UTAUT) tool cross-culturally. People and Computers XXI HCI.But Not as We Know It Proceedings of HCI 2007: The 21st British HCI Group Annual Conference, 2(September). https://doi.org/10.14236/ewic/hci2007.67

[26] Salwani, M. I., Marthandan, G., Norzaidi, M. D., \& Chong, S. C. (2009). E-commerce usage and business performance in the Malaysian tourism sector: Empirical analysis. Information Management and Computer Security. https://doi.org/10.1108/09685220910964027

[27] Schillewaert, N., Ahearne, M. J., Frambach, R. T., \& Moenaert, R. K. (2005). The adoption of information technology in the sales force. Industrial Marketing Management. https://doi.org/10.1016/j.indmarman.2004.09.013

[28] Soh, C., Kien, S. S., \& Tay-Yap, J. (2000). Enterprise resource planning: cultural fits and misfits: is ERP a universal solution? Communications of the ACM. https://doi.org/10.1145/332051.332070

[29] Sternad, S., \& Bobek, S. (2013). Impacts of TAM-based External Factors on ERP Acceptance. Procedia Technology. https://doi.org/10.1016/j.protcy.2013.12.004

[30] Thiesse, F., Staake, T., Schmitt, P., \& Fleisch, E. (2011). The rise of the "next-generation bar code": An international RFID adoption study. Supply Chain Management. https://doi.org/10.1108/13598541111155848

[31] Tornatzky, L. G. and F. (1990). The processes of technological innovation, Lexington books, Lexington, MANo Title.

[32] Venkatesh, V. (2016). The Unified Theory of Acceptance and Use of Technology: A SYNTHESIS AND THE ROAD AHEAD. International Journal of Sociotechnology and Knowledge Development, 17(5), 328376. https://doi.org/10.4018/ijskd.2020070105

[33] Wang, E. T. G., \& Chen, J. H. F. (2006). Effects of internal support and consultant quality on the consulting process and ERP system quality. Decision Support Systems, 42(2), 1029-1041. https://doi.org/10.1016/j.dss.2005.08.005

[34] Wang, E. T. G., Shih, S. P., Jiang, J. J., \& Klein, G. (2008). The consistency among facilitating factors and ERP implementation success: A holistic view of fit. Journal of Systems and Software, 81(9), 1609-1621. https://doi.org/10.1016/j.jss.2007.11.722

[35] Williams, M. D., Dwivedi, Y. K., Lal, B., \& Schwarz, A. (2009). Contemporary trends and issues in IT adoption and diffusion research. Journal of Information Technology. https://doi.org/10.1057/jit.2008.30

[36] Wu, W. W. (2011). Developing an explorative model for SaaS adoption. Expert Systems with Applications. https://doi.org/10.1016/j.eswa.2011.05.039

[37] Zhenhua, L., Qingfei, M., \& Shaobo, J. (2008). A comprehensive review of research in IT adoption. 2008 International Conference on Wireless Communications, Networking and Mobile Computing, WiCOM 2008. https://doi.org/10.1109/WiCom.2008.2808

[38] Zhu, K. and Kraemer, K. L. (2005). Post-adoption variations in usage and value of e-business by organizations: cross-country evidence from the retail industry. 16(1), 61-84.

[39] Zhu, K., Kraemer, K. L., Xu, S., \& Dedrick, J. (2004). Information technology payoff in E-Business environments: An international perspective on value creation of E-Business in the financial services industry. Journal of Management Information Systems. https://doi.org/10.1080/07421222.2004.11045797

[40] Zhu, K., Kraemer, K., \& Xu, S. (2003). Electronic business adoption by European firms: A cross-country assessment of the facilitators and inhibitors. European Journal of Information Systems. https://doi.org/10.1057/palgrave.ejis.3000475 